\title{
Short-Form Charlson Comorbidity Index for Assessment of Perioperative Mortality After Radical Cystectomy
}

\author{
Paolo Dell'Oglio, MD ${ }^{\mathrm{a}, \mathrm{b}, \mathrm{c}, *}$; Zhe Tian ${ }^{\mathrm{a}, \mathrm{d}, *}$; Sami-Ramzi Leyh-Bannurah, MDa,e; Vincent Trudeau, MD ${ }^{\mathrm{a}, \mathrm{f}}$; \\ Alessandro Larcher, MD ${ }^{\mathrm{b}, \mathrm{c}}$; Marco Moschini, MD ${ }^{\mathrm{b}, \mathrm{c}}$; Ettore Di Trapani, MD ${ }^{\mathrm{b}, \mathrm{c}}$; Umberto Capitanio, MD ${ }^{\mathrm{b}, \mathrm{c}}$; \\ Alberto Briganti, MD ${ }^{\mathrm{b}, \mathrm{c}}$; Francesco Montorsi, MD ${ }^{\mathrm{b}, \mathrm{c}}$; Fred Saad, MDf; and Pierre I. Karakiewicz, MD ${ }^{\mathrm{a}, \mathrm{f}}$
}

\begin{abstract}
Background: The Deyo adaptation of the Charlson comorbidity index (DaCCl), which relies on 17 comorbid condition groupings, represents one of the most frequently used baseline comorbidity assessment tools in retrospective database studies. However, this index is not specific for patients with bladder cancer (BCa) treated with radical cystectomy (RC). The goal of this study was to develop a short-form of the original $\mathrm{DaCCl}$ (DaCCI-SF) that may specifically predict 90-day mortality after RC, with equal or better accuracy. Patients and Methods: Between 2000 and 2009, we identified 7,076 patients in the SEER-Medicare database with stage T1 through T4 nonmetastatic BCa treated with RC. We randomly divided the population into development $(n=6,076)$ and validation $(n=1,000)$ cohorts. Within the development cohort, logistic regression models tested the ability to predict 90-day mortality with various iterations of the $\mathrm{DaCCl}$-SF, wherein $<17$ original comorbid condition groupings were included after adjusting for age, sex, race, T stage, and $\mathrm{N}$ stage. We relied on the Akaike information criterion to identify the most parsimonious and informative set of comorbid condition groupings. Accuracy of the DaCCl and the DaCCl-SF was tested in the external validation cohort. Results: Within the development cohort, the most parsimonious and informative model resulted in the inclusion of 3 of the $17(17.6 \%)$ original comorbid condition groupings: congestive heart failure, cerebrovascular disease, and chronic pulmonary disease. Within the validation cohort, the accuracy was $68.4 \%$ for the DaCCI versus $69.7 \%$ for the DaCCI-SF. Higher accuracy of the DaCCI-SF was Confirmed in subgroup analyses performed according to age ( $\leq 75$ vs $>75$ years), stage (organ-confined vs non-organ-confined), type of diversion (ilealconduit vs non-ileal-conduit), and treatment period. Conclusions: DaCCI-SF relies on $17.6 \%$ of the original comorbid condition groupings and provides higher accuracy for predicting 90-day mortality after RC compared with the original DaCCl, especially in most contemporary patients.
\end{abstract}

J Natl Compr Canc Netw 2017;15(3):327-333

\section{Background}

Radical cystectomy (RC) is one of the most invasive surgeries in urologic oncology, with an elevated perioperative mortality that can reach $14.8 \%$ in elderly patients, according to the SEER-Medicare database. ${ }^{1}$ SEER-Medicare

From a Cancer Prognostics and Health Outcomes Unit, University of Montreal Health Center, Montreal, Canada; bUnit of Urology, University Vita-Salute San Raffaele, IRCCS San Raffaele Scientific Institute, Milan, Italy; 'Division of Experimental Oncology, Urological Research Institute, IRCCS San Raffaele Scientific Institute, Milan, Italy; ${ }^{d}$ Department of Epidemiology, Biostatistics, and Occupational Health, McGill University, Montreal, Canada; eMartini-Clinic, Prostate Cancer Center HamburgEppendorf, Hamburg, Germany; and fDepartment of Urology, University of Montreal Health Center, Montreal, Canada.

*These authors contributed equally.

Submitted June 11, 2016; accepted for publication November 28, 2016. represents one of the most widely used populationbased repositories of urologic oncology data. Within SEER-Medicare-based analyses, including those focusing on perioperative mortality, the Deyo adaptation of the Charlson comorbidity index $(\mathrm{DaCCI})$ is

The authors have disclosed that they have no financial interests, arrangements, affiliations, or commercial interests with the manufacturers of any products discussed in this article or their competitors.

Author contributions: Study conception and design: Dell'Oglio, Tian, Karakiewicz. Acquisition of data: Dell'Oglio, Tian. Analysis and interpretation of data: Dell'Oglio, Tian, Karakiewicz. Drafting of manuscript: Dell'Oglio, Tian, Karakiewicz. Critical revision: Dell'Oglio, Tian, Leyh-Bannurah, Trudeau, Larcher, Moschini, Di Trapani, Capitanio, Briganti, Montorsi, Saad, Karakiewicz. Statistical analysis: Dell'Oglio, Tian. Study supervision: Karakiewicz.

Correspondence: Paolo Dell'Oglio, MD, Cancer Prognostics and Health Outcomes Unit, 264 Boulevard Rene-Levesque East, Room 228, Montreal QC H2X 1P1, Canada. E-mail: paolo.delloglio@gmail.com 
Dell'Oglio et al

customarily used., ${ }^{2,3}$ This index was originally developed $^{3}$ with the intent of predicting 1 -year mortality in admitted medical patients. Several investigators ${ }^{4,5}$ suggested the development of a comorbidity index specific to patients with bladder cancer (BCa) treated with RC for specific prediction of various mortality end points, including perioperative mortality. To address this unmet need, we attempted to identify a short-form of the original DaCCI (DaCCI-SF), using the most parsimonious and informative set of predictors of 90-day mortality after RC. Specifically, we hypothesized that a simplified comorbidity index, which rests on a fraction of the 17 original comorbid condition groupings that form the original DaCCI, may be developed with equal or better accuracy.

\section{Patients and Methods}

\section{Data Source}

A SEER-Medicare-specific approval was obtained through the NCI. The current study relied on the SEER-Medicare linked database. The SEER registries identify $28 \%$ of all cancer cases in the United States, and Medicare insures approximately $97 \%$ of all Americans aged $\geq 65$ years. Linkage to the SEER database is complete for approximately $93 \%$ of cases. ${ }^{6}$

\section{Study Population}

In the SEER-Medicare-linked database, we identified 10,522 patients with nonmetastatic (cMO) urothelial carcinoma of the urinary bladder (UCUB) treated with RC between 2000 and 2009. Patients not enrolled in Medicare Parts A or B for a minimum of 12 months before their first recorded diagnosis and for a minimum of 3 months after RC were not considered. Patients who had health maintenance organization enrollment in the year before or for any period after diagnosis were also excluded. To ensure that all subjects had $\geq 1$ year of claims from which comorbidities were derived, only those aged $\geq 66$ years were considered. This resulted in a final population of 7,076 assessable patients with UCUB treated with RC.

\section{Variable Definition}

Patient characteristics included age at diagnosis, sex, race (white vs black vs other), and the 17 comorbid condition groupings contributing to the original $\mathrm{DaCCI}^{2}$ (myocardial infarction, congestive heart failure [CHF], peripheral vascular disease, cerebrovascular disease, dementia, chronic pulmonary disease, rheumatologic disease, peptic ulcer disease, mild liver disease, diabetes, diabetes with chronic complications, hemiplegia or paraplegia, renal disease, leukemia/lymphoma, moderate or severe liver disease, metastatic solid tumor, AIDS). All ICD-9-CM diagnostic codes that identified these 17 comorbid condition groupings were established by classifying inpatient and outpatient claims and physicians billing claims for the 12 -month interval preceding RC. Tumor characteristics included pathologic stage (T1, T2, T3, and T4) and lymph node stage $(\mathrm{NO}, \mathrm{N}+, \mathrm{Nx})$.

\section{Outcomes}

The end point our study was to identify the most parsimonious and informative set of comorbid conditions among the 17 original comorbid condition groupings included in the original $\mathrm{DaCCI}$ in order to predict 90-day mortality after RC, which was defined as overall mortality.

\section{Statistical Analyses}

Our analyses consisted of 5 steps. First, we randomly divided the population into development $(n=6,076)$ and validation $(n=1,000)$ cohorts. Second, within the development cohort, we relied on logistic regression models to test the ability of the 17 original comorbid condition groupings included in the original DaCCI to predict 90 -day mortality after adjusting for age, sex, race, pathologic $\mathrm{T}$ stage, and $\mathrm{N}$ stage. Subsequently, the same analyses were performed to test the ability to predict 90-day mortality with various iterations of the DaCCI-SF, which included $<17$ of the original comorbid condition groupings. We relied on the Akaike information criterion (AIC) ${ }^{7,8}$ to identify the most parsimonious and informative set of comorbid condition groupings for inclusion in the DaCCI-SF.

Third, within the validation cohort we tested the accuracy of the original DaCCI to predict 90-day mortality after RC, after adjusting for age, sex, race, pathologic $\mathrm{T}$ stage, and $\mathrm{N}$ stage. Subsequently, we tested the accuracy of the DaCCI-SF that was identified within the development cohort as the most parsimonious and informative. To further illustrate the DaCCI-SF's performance, receiver operating characteristic (ROC) curves were generated to compare models using the DaCCI-SF, the DaCCI, and no adjustment for comorbidity. 
Finally, as a way to perform sensitivity analyses and to confirm the robustness of our findings, within the external validation cohort we tested the ability to predict 90-day mortality for the original $\mathrm{DaCCI}$ and the DaCCI-SF in specific patient subgroups, which included age $(\leq 75$ vs $>75)$, stage (organconfined vs non-organ-confined), type of diversion (ileal-conduit vs non-ileal-conduit), and treatment period (2005-2009).

All statistical tests were performed using the RStudio graphical interface v.0.98 for R software environment v.3.0.2 (R Foundation, Vienna, Austria). All tests were 2 -sided with a significance level set at $P<.05$.

\section{Results}

\section{Testing Population}

The median age in the development and validation cohorts was 75 years. Most patients were male (71.4\% and $71.9 \%)$, white $(90.2 \%$ and $89.6 \%)$, and had pathologic T2 $\mathrm{BCa}(35.9 \%$ and $34.7 \%)$ and $\mathrm{pNO}$ stage $(64.5 \%$ and $63.0 \%$; Table 1$)$. Overall, 90-day mortality rates after RC were $10.7 \%$ and $11.2 \%$, respectively, within development and validation cohorts (Table 2). Within the 17 comorbid-condition groupings of the original $\mathrm{DaCCI}$, chronic pulmonary disease was the most frequent, followed by diabetes and cerebrovascular disease (Table 1). Conversely, virtually no patient was identified with dementia, leukemia/lymphoma, AIDS, or metastatic solid tumors of origin other than BCa, all of which represent $\mathrm{DaCCI}$ groupings.

In multivariable analyses performed in the development cohort, of 17 comorbid condition groupings, 5 were independent predictors of 90 -day mortality after RC: CHF (odds ratio [OR], 1.49; P<.001), cerebrovascular disease $(\mathrm{OR}, 1.40 ; P=.001)$, chronic pulmonary disease (OR, $1.40 ; P<.001)$, rheumatologic disease $(\mathrm{OR}, 1.52 ; P=.04)$, and renal disease (OR, 1.47; $P=.003$; Table 3 ). Conversely, myocardial infarction, peripheral vascular disease, dementia, peptic ulcer disease, diabetes, diabetes with chronic complications, hemiplegia or paraplegia, moderate or severe liver disease, AIDS, and leukemia/lymphoma failed to reach the independent predictors status.

Analyses performed in the development cohort, aimed at identifying the most parsimonious and informative DaCCI-SF, resulted in inclusion of 3 of the 17 $(17.6 \%)$ original comorbid condition groupings includ-

\begin{tabular}{|c|c|c|c|}
\hline Variables & $\begin{array}{c}\text { Development } \\
\text { Cohort } \\
(\mathrm{N}=6,076)\end{array}$ & $\begin{array}{c}\text { Validation } \\
\text { Cohort } \\
(\mathrm{N}=1,000)\end{array}$ & $\begin{array}{c}P \\
\text { Value }\end{array}$ \\
\hline \multicolumn{3}{|l|}{ Age at diagnosis, y } & .5 \\
\hline Median & 75 & 75 & \\
\hline IQR & $70.2-79.8$ & $70.4-80.1$ & \\
\hline \multicolumn{3}{|l|}{ Sex, n (\%) } & .8 \\
\hline Male & $4,341(71.4)$ & 719 (71.9) & \\
\hline Female & $1,735(28.6)$ & $281(28.1)$ & \\
\hline \multicolumn{3}{|l|}{ Race, n (\%) } & .6 \\
\hline Other & $302(5)$ & $57(5.7)$ & \\
\hline White & $5,483(90.2)$ & $896(89.6)$ & \\
\hline Black & $291(4.8)$ & $47(4.7)$ & \\
\hline \multicolumn{3}{|c|}{ Pathologic T stage, n (\%) } & .02 \\
\hline $\mathrm{T} 1$ & $1,586(26.1)$ & $271(27.1)$ & \\
\hline $\mathrm{T} 2$ & $2,181(35.9)$ & $347(34.7)$ & \\
\hline T3 & $1,563(25.7)$ & $228(22.8)$ & \\
\hline T4 & $746(12.3)$ & $154(15.4)$ & \\
\hline \multicolumn{3}{|l|}{$\mathrm{N}$ status, $\mathrm{n}(\%)$} & .6 \\
\hline No & $3,917(64.5)$ & $630(63)$ & \\
\hline Nx & $1,340(22.1)$ & $227(22.7)$ & \\
\hline $\mathrm{N}+$ & $819(13.5)$ & $143(14.3)$ & \\
\hline $\begin{array}{l}\text { Myocardial } \\
\text { infarction }\end{array}$ & $534(8.8)$ & $90(9)$ & .7 \\
\hline $\begin{array}{l}\text { Congestive heart } \\
\text { failure }\end{array}$ & 790 (13) & $127(12.7)$ & .9 \\
\hline $\begin{array}{l}\text { Peripheral vascular } \\
\text { disease }\end{array}$ & $554(9.1)$ & $78(7.8)$ & .2 \\
\hline $\begin{array}{l}\text { Cerebrovascular } \\
\text { disease }\end{array}$ & $1,108(18.2)$ & $176(17.6)$ & .7 \\
\hline Dementia & * & * & .4 \\
\hline $\begin{array}{l}\text { Chronic pulmonary } \\
\text { disease }\end{array}$ & $1,911(31.5)$ & $325(32.5)$ & .5 \\
\hline $\begin{array}{l}\text { Rheumatologic } \\
\text { disease }\end{array}$ & $179(2.9)$ & $33(3.3)$ & .6 \\
\hline Peptic ulcer disease & $156(2.6)$ & $25(2.5)$ & .9 \\
\hline Mild liver disease & $35(0.6)$ & * & .5 \\
\hline Diabetes & $1,622(26.7)$ & $252(25.2)$ & .3 \\
\hline $\begin{array}{l}\text { Diabetes with chronic } \\
\text { complications }\end{array}$ & $345(5.7)$ & $43(4.3)$ & .09 \\
\hline $\begin{array}{l}\text { Hemiplegia or } \\
\text { paraplegia }\end{array}$ & $54(0.9)$ & * & .9 \\
\hline Renal disease & $548(9)$ & $94(9.4)$ & .7 \\
\hline Leukemia/lymphoma & * & * & .9 \\
\hline $\begin{array}{l}\text { Moderate or severe } \\
\text { liver disease }\end{array}$ & $13(0.2)$ & * & .9 \\
\hline AIDS & * & * & .9 \\
\hline
\end{tabular}

Comorbidities are presented according to comorbid condition groupings of the Deyo adaptation of the Charlson comorbidity index. Abbreviation: IQR, interquartile range.

*Masked for protection of patient confidentiality reasons, as per $\mathrm{NCl}$ regulations. 
Dell'Oglio et al

\begin{tabular}{|c|c|c|}
\hline Variables & $\begin{array}{c}\text { Development } \\
\text { Cohort } \\
n=649(10.7 \%)\end{array}$ & $\begin{array}{c}\text { Validation } \\
\text { Cohort } \\
\mathrm{n}=112(11.2 \%)\end{array}$ \\
\hline \multicolumn{3}{|l|}{ Age at diagnosis, y } \\
\hline Median & 77.7 & 78.5 \\
\hline IQR & $72.6-81.9$ & $73.2-83.1$ \\
\hline \multicolumn{3}{|l|}{ Sex, n (\%) } \\
\hline Male & $438(67.5)$ & $73(65.2)$ \\
\hline Female & $211(32.5)$ & $39(34.8)$ \\
\hline \multicolumn{3}{|l|}{ Race, n (\%) } \\
\hline Other & $29(4.5)$ & * \\
\hline White & $581(89.5)$ & $101(90.2)$ \\
\hline Black & $39(6)$ & * \\
\hline \multicolumn{3}{|l|}{ Pathologic T stage, n (\%) } \\
\hline $\mathrm{T} 1$ & $130(20)$ & $20(17.9)$ \\
\hline $\mathrm{T} 2$ & $184(28.4)$ & $32(28.6)$ \\
\hline T3 & $193(29.7)$ & $37(33)$ \\
\hline T4 & $142(21.9)$ & $23(20.5)$ \\
\hline \multicolumn{3}{|l|}{ N status, n (\%) } \\
\hline No & $361(55.6)$ & $59(52.7)$ \\
\hline $\mathrm{Nx}$ & $165(25.4)$ & $31(27.7)$ \\
\hline $\mathrm{N}+$ & $123(19)$ & $22(19.6)$ \\
\hline Myocardial infarction & $70(10.8)$ & $14(12.5)$ \\
\hline Congestive heart failure & $145(22.3)$ & $23(20.5)$ \\
\hline Peripheral vascular disease & $80(12.3)$ & $12(10.7)$ \\
\hline Cerebrovascular disease & $170(26.2)$ & $28(25)$ \\
\hline Dementia & * & * \\
\hline Chronic pulmonary disease & $256(39.4)$ & $43(38.4)$ \\
\hline Rheumatologic disease & $31(4.8)$ & * \\
\hline Peptic ulcer disease & $25(3.9)$ & * \\
\hline Mild liver disease & * & * \\
\hline Diabetes & 207 (31.9) & $35(31.2)$ \\
\hline $\begin{array}{l}\text { Diabetes with chronic } \\
\text { complications }\end{array}$ & $51(7.9)$ & * \\
\hline Hemiplegia or paraplegia & * & * \\
\hline Renal disease & $96(14.8)$ & $14(12.5)$ \\
\hline Leukemia/lymphoma & * & * \\
\hline Moderate or severe liver disease & * & * \\
\hline AIDS & * & * \\
\hline
\end{tabular}

Comorbidities are presented according to comorbid condition groupings of the Deyo adaptation of the Charlson comorbidity index. Abbreviation: IQR, interquartile range.

* Masked for protection of patient confidentiality reasons, as per $\mathrm{NCl}$ regulations. ed in the original DaCCI: CHF (OR, 1.65; $P<.001)$, cerebrovascular disease $(\mathrm{OR}, 1.45 ; P<.001)$, and chronic pulmonary disease $(\mathrm{OR}, 1.43 ; \mathrm{P}<.001$; Table 3$)$

\section{External Validation}

Within the validation cohort, the individual accuracy figures for predicting 90-day mortality after RC for the 3 comorbid condition groupings were $68.5 \%$ for $\mathrm{CHF}, 67.9 \%$ for cerebrovascular disease, and $67.3 \%$ for chronic pulmonary disease. The combination of these 3 comorbid condition groupings that formed the DaCCI-SF yielded an accuracy of $69.7 \%$ versus $68.4 \%$ for the original DaCCI (Table 4 ). ROC curves for the comparison of these models are shown in supplemental eFigure 1 (available with this article at JNCCN.org).

\section{Subgroup Analyses}

Lastly, we tested the accuracy of the DaCCI-SF for predicting 90 -day mortality after $\mathrm{RC}$ relative to the original $\mathrm{DaCCI}$ in specific patient subgroups. In brief, the DaCCI-SF predicted 90-day mortality after $\mathrm{RC}$ with higher accuracy relative to the original DaCCI in all subgroups, without exception (Table 4).

\section{Discussion}

The study objective was to devise a short-form of the original DaCCI (DaCCI-SF) with equal or better accuracy for predicting 90-day mortality after RC. The rationale for such analysis stems from the absence of a contemporary, validated tool in the specific setting of patients with BCa treated with RC. ${ }^{5}$

Our analyses demonstrated several important findings. First, 1 out of 10 patients treated with RC died within 90 days. This observation validates the importance of perioperative mortality as an important clinical concept. Moreover, it calls for a contemporary, validated tool for analyses of 90-day mortality after RC that is ideally simpler than the relatively cumbersome $\mathrm{DaCCI},{ }^{2}$ but offers same or better accuracy.

Second, of 17 tested comorbid condition groupings that contribute to the original $\mathrm{DaCCI}$, only 5 achieved independent predictor status in models aimed at predicting 90-day mortality after RC (CHF, cerebrovascular disease, chronic pulmonary disease, rheumatologic disease, and renal disease). Several of 


\begin{tabular}{|c|c|c|c|c|}
\hline & \multicolumn{2}{|l|}{$\mathrm{DaCCl}$} & \multicolumn{2}{|c|}{ DaCCI-SF } \\
\hline & $\begin{array}{l}\text { Multivariable } \\
\text { OR }(95 \% \mathrm{Cl})\end{array}$ & $\begin{array}{c}P \\
\text { Value }\end{array}$ & $\begin{array}{l}\text { Multivariable } \\
\text { OR }(95 \% \mathrm{Cl})\end{array}$ & $\begin{array}{c}P \\
\text { Value }\end{array}$ \\
\hline $\begin{array}{l}\text { Myocardial } \\
\text { infarction }\end{array}$ & $1.04(0.78-1.37)$ & .8 & - & - \\
\hline $\begin{array}{l}\text { Congestive heart } \\
\text { failure }\end{array}$ & $1.49(1.19-1.86)$ & $<.001$ & $1.65(1.33-2.05)$ & $<.001$ \\
\hline $\begin{array}{l}\text { Peripheral vascular } \\
\text { disease }\end{array}$ & $1.04(0.79-1.36)$ & .8 & - & - \\
\hline $\begin{array}{l}\text { Cerebrovascular } \\
\text { disease }\end{array}$ & $1.4(1.14-1.71)$ & .001 & $1.45(1.19-1.77)$ & $<.001$ \\
\hline Dementia & $0.8(0.07-9.43)$ & .9 & - & - \\
\hline $\begin{array}{l}\text { Chronic pulmonary } \\
\text { disease }\end{array}$ & $1.4(1.17-1.67)$ & $<.001$ & $1.43(1.2-1.7)$ & $<.001$ \\
\hline $\begin{array}{l}\text { Rheumatologic } \\
\text { disease }\end{array}$ & $1.52(1.01-2.3)$ & .04 & - & - \\
\hline Peptic ulcer disease & $1.31(0.83-2.07)$ & .2 & - & - \\
\hline Mild liver disease & $0.28(0.04-2.06)$ & .2 & - & - \\
\hline Diabetes & $1.2(0.98-1.46)$ & .08 & - & - \\
\hline $\begin{array}{l}\text { Diabetes } \\
\text { with chronic } \\
\text { complications }\end{array}$ & $1.15(0.81-1.64)$ & .4 & - & - \\
\hline $\begin{array}{l}\text { Hemiplegia or } \\
\text { paraplegia }\end{array}$ & $0.99(0.43-2.27)$ & .9 & - & - \\
\hline Renal disease & $1.47(1.14-1.89)$ & .003 & - & - \\
\hline $\begin{array}{l}\text { Leukemia/ } \\
\text { lymphoma }\end{array}$ & $3.26(0.33-32.49)$ & .3 & - & - \\
\hline $\begin{array}{l}\text { Moderate or severe } \\
\text { liver disease }\end{array}$ & $0.52(0.06-4.24)$ & .5 & - & - \\
\hline AIDS & $1.0(0.1-9.1)$ & .9 & - & - \\
\hline
\end{tabular}

Abbreviations: DaCCl, Deyo adaptation of the Charlson comorbidity index; $\mathrm{DaCCl}-\mathrm{SF}$, a short-form of the original $\mathrm{DaCCl}$; OR, odds ratio. aThe models were adjusted for age, sex, race (white vs black vs others), pathologic T stage (T1 vs T2 vs T3 vs T4), and pathologic $\mathrm{N}$ stage (NO vs $\mathrm{N}+$ vs $\mathrm{Nx}$ ).

these entities have an established role in potentially predicting perioperative mortality. ${ }^{9-13}$ However, it is also noteworthy that 12 of the 17 comorbid condition groupings failed to achieve independent predictor status. Of these, several noteworthy entities, such as myocardial infarction, diabetes, or diabetes with chronic complications, failed to make the cut. This observation indicates that even though some entities predict overall mortality, ${ }^{14-20}$ they may not be capable of accurately predicting 90-day mortality in the specific setting of RC for BCa. It is also important to note that, based on their low or even marginal prevalence among patients with BCa treated with RC (Table 1), some of the original comorbid condition groupings, such as AIDS and leukemia/lymphoma, were not expected to accurately predict 90-day mortality. This observation validates the need for the development of a contemporary and validated tool for predicting 90-day mortality after RC, as was done in the current study.

Third, to the best of our knowledge, we are the first to devise and test a DaCCI-SF for predicting 90-day mortality after RC. Our results showed that the DaCCI-SF performs better and is substantially simpler than the original DaCCI. Specifically, the DaCCI-SF relies on only 3 comorbid condition groupings and achieved $69.7 \%$ accuracy compared with $68.4 \%$ with the original DaCCI, which relies on 17 comorbid condition groupings. Higher accuracy of the DaCCI-SF was invariably confirmed in all subgroup analyses performed according to age ( $\leq 75$ vs $>75$ years), stage (organ-confined vs non-organ-confined), type of diversion (ileal-conduit vs non-ileal-conduit), and treatment period. The increase in accuracy of the DaCCI-SF relative to the original DaCCI was not overwhelming, except in the most contemporary patients, namely those treated between 2005 and 2009. This was expected considering the fact that we are proposing a simplification of the DaCCI that was originally developed in admitted medical patients and not in the specific setting of patients with BCa treated with RC.

Fourth, we performed a detailed assessment of individual groupings of specific comorbid conditions to identify the most and least informative one based on individual consideration. These analyses revealed that the accuracy was $68.5 \%$ for $\mathrm{CHF}, 67.9 \%$ for cerebrovascular disease, and $67.3 \%$ for chronic pulmonary disease.

Previous studies proposed a simplification of the $\mathrm{CCI}^{21,22}$ or developed a new comorbidity score ${ }^{23-29}$ in a specific disease setting. However, in all of these studies, the focus did not represent patients with $\mathrm{BCa}$ treated with $\mathrm{RC}$, and therefore these indexes are not applicable in the BCa setting. This is important to underline, because comorbidity profiles differ depending on the disease.

Clinical implications of our findings are severalfold. First, we demonstrated that the original DaCCI can be shortened without loss of accuracy when prediction of 90-day mortality after RC represents the end point. It may be replaced with a DaCCISF that relies on only 3 comorbid condition groupings, instead of 17; this applies to the specific population of patients with $\mathrm{BCa}$ treated with RC. Therefore, we 
Dell'Oglio et al

\begin{tabular}{|c|c|c|}
\hline & $\mathrm{DaCCl}$ & DaCCI-SF \\
\hline Overall population & $68.4 \%$ & $69.7 \%$ \\
\hline \multicolumn{3}{|l|}{ Age } \\
\hline$\leq 75$ y & $65.0 \%$ & $66.8 \%$ \\
\hline$>75 y$ & $63.3 \%$ & $64.0 \%$ \\
\hline \multicolumn{3}{|l|}{ Stage } \\
\hline Organ-confined & $65.5 \%$ & $65.8 \%$ \\
\hline Non-organ-confined & $73.4 \%$ & $76.0 \%$ \\
\hline \multicolumn{3}{|l|}{ Type of diversion } \\
\hline Ileal-conduit & $66.6 \%$ & $66.8 \%$ \\
\hline Non-ileal-conduit & $72.7 \%$ & $76.8 \%$ \\
\hline $\begin{array}{l}\text { Most contemporary patients } \\
(2005-2009)\end{array}$ & $60.3 \%$ & $68.0 \%$ \\
\hline
\end{tabular}

Abbreviations: $\mathrm{DaCCl}$, Deyo adaptation of the Charlson comorbidity index; DaCCI-SF, a short-form of the original $\mathrm{DaCCl}$.

proposed a more user-friendly, less labor-intensive and time-consuming comorbidity index that is intended for use in retrospective analyses performed using largescale BCa databases, in which ICD-9-CM diagnostic codes are found. Moreover, one comorbidity grouping, $\mathrm{CHF}$, was equally as accurate as with the original $\mathrm{DaCCI}$. Therefore, investigators searching for adjustment for comorbidity in small cohorts, in which the number of degrees of freedom is restricted, may rely on this single variable. Conversely, in larger database analyses, use of the DaCCI-SF, which relies on the 3 comorbid condition groupings, should be encouraged if sample size permits.

Other approaches are recommended in retrospective databases in which American Society of Anesthesiologists ${ }^{30}$ or other coding schemes ${ }^{31,32}$ are used, because such methods were shown to result in higher accuracy in predicting 90-day mortality after $\mathrm{RC}$ than the $\mathrm{CCI} .^{33}$ However, such coding schemes are not widely accepted and cannot be applied in administrative databases, such as SEER-Medicare, which uses ICD-9-CM codes.

Despite the strengths of our study, it is not devoid of limitations. First, our findings are not generalizable, because they originated from the SEERMedicare setting. Second, our tools may not be applicable to younger patients, given the fact that SEER-Medicare relies on patients aged $\geq 66$ years. Third, despite the fact that we devised the first DaCCI-SF for predicting 90-day mortality in contemporary patients with $\mathrm{BCa}$ treated with $\mathrm{RC}$, there might be some comorbid conditions ${ }^{34,35}$ that are not included in this index because of the nature of the original CCI, that are more represented among patients with $\mathrm{BCa}$, and that might be more strictly related to perioperative mortality after RC. Future studies are needed to develop a new comorbidity score for the specific prediction of 90-day mortality in patients who have undergone RC, analyzing all possible individual comorbid conditions to identify those that satisfy the criteria of maximal accuracy and parsimony for predicting perioperative mortality after RC.

\section{Conclusions}

In the current study, we devised the first short-form version of the DaCCI for predicting 90-day mortality in patients with $\mathrm{BCa}$ treated with $\mathrm{RC}$. The DaCCISF relies on only $3(17.6 \%)$ of the 17 original comorbid condition groupings and provides higher accuracy for predicting 90-day mortality after RC compared with the original $\mathrm{DaCCI}$, especially in most contemporary patients.

\section{References}

1. Schiffmann J, Gandaglia G, Larcher A, et al. Contemporary 90-day mortality rates after radical cystectomy in the elderly. Eur J Surg Oncol 2014;40:1738-1745

2. Deyo RA, Cherkin DC, Ciol MA. Adapting a clinical comorbidity index for use with ICD-9-CM administrative databases. J Clin Epidemiol 1992;45:613-619.

3. Charlson ME, Pompei P, Ales KL, MacKenzie CR. A new method of classifying prognostic comorbidity in longitudinal studies: development and validation. J Chronic Dis 1987;40:373-383.

4. Miller DC, Taub DA, Dunn RL, et al. The impact of co-morbid disease on cancer control and survival following radical cystectomy. J Urol 2003;169:105-109.

5. Alfred Witjes J, Lebret T, Comperat EM, et al. Updated 2016 EAU guidelines on muscle-invasive and metastatic bladder cancer. Eur Urol 2017;71:462-475.

6. Warren JL, Klabunde CN, Schrag D, et al. Overview of the SEER Medicare data: content, research applications, and generalizability to the United States elderly population. Med Care 2002;40(8 Suppl):IV-3-18.

7. Burnham KP, Anderson DR. Model Selection and Multimodel Inference: A Practical Information-Theoretic Approach. New York, NY: Springer Science \& Business Media; 2002.

8. Burnham KP, Anderson DR. Multimodel inference understanding AIC and BIC in model selection. Sociol Methods Res 2004;33:261-304.

9. Hammill BG, Curtis LH, Bennett-Guerrero E, et al. Impact of heart failure on patients undergoing major noncardiac surgery. Anesthesiology 2008;108:559-567.

10. Higgins TL, Estafanous FG, Loop FD, et al. Stratification of morbidity and mortality outcome by preoperative risk factors in coronary artery bypass patients. A clinical severity score. JAMA 1992;267:2344-2348. 
11. Jorgensen ME, Torp-Pedersen C, Gislason GH, et al. Time elapsed after ischemic stroke and risk of adverse cardiovascular events and mortality following elective noncardiac surgery. JAMA 2014;312:269-277.

12. Licker MJ, Widikker I, Robert J, et al. Operative mortality and respiratory complications after lung resection for cancer: impact of chronic obstructive pulmonary disease and time trends. Ann Thorac Surg 2006;81:1830-1837.

13. Virani S, Michaelson JS, Hutter MM, et al. Morbidity and mortality after liver resection: results of the patient safety in surgery study. J Am Coll Surg 2007;204:1284-1292.

14. Livhits M, Ko CY, Leonardi MJ, et al. Risk of surgery following recent myocardial infarction. Ann Surg 2011;253:857-864.

15. Auerbach A, Goldman L. Assessing and reducing the cardiac risk of noncardiac surgery. Circulation 2006;113:1361-1376.

16. Krolikowska M, Kataja M, Poyhia R, et al. Mortality in diabetic patients undergoing non-cardiac surgery: a 7-year follow-up study. Acta Aanaesthesiol Scand 2009;53:749-758.

17. Emerging Risk Factors Collaboration, Seshasai SR, Kaptoge S, et al Diabetes mellitus, fasting glucose, and risk of cause-specific death. N Engl J Med 2011;364:829-841.

18. Jee $\mathrm{SH}$, Ohrr H, Sull JW, et al. Fasting serum glucose level and cancer risk in Korean men and women. JAMA 2005;293:194-202.

19. Thourani $\mathrm{VH}$, Weintraub WS, Stein $B$, et al. Influence of diabetes mellitus on early and late outcome after coronary artery bypass grafting. Ann Thorac Surg 1999;67:1045-1052.

20. Oh JJ, Kang MY, Jo JK, et al. Association between diabetes mellitus and oncological outcomes in bladder cancer patients undergoing radical cystectomy. Int J Urol 2015;22:1112-1117.

21. Patel HD, Kates M, Pierorazio PM, et al. Comorbidities and causes of death in the management of localized T1a kidney cancer. Int J Urol 2014;21:1086-1092.

22. Hemmelgarn BR, Manns BJ, Quan H, Ghali WA. Adapting the Charlson comorbidity index for use in patients with ESRD. Am J Kidney Dis 2003;42:125-132.

23. Klabunde $\mathrm{CN}$, Legler JM, Warren JL, et al. A refined comorbidity measurement algorithm for claims-based studies of breast, prostate, colorectal, and lung cancer patients. Ann Epidemiol 2007;17:584590 .
24. Fleming ST, Rastogi A, Dmitrienko A, Johnson KD. A comprehensive prognostic index to predict survival based on multiple comorbidities: a focus on breast cancer. Med Care 1999;37:601-614.

25. Fleming ST, Pearce KA, McDavid K, Pavlov D. The development and validation of a comorbidity index for prostate cancer among black men. J Clin Epidemiol 2003;56:1064-1075.

26. Colinet B, Jacot W, Bertrand D, et al. A new simplified comorbidity score as a prognostic factor in non-small-cell lung cancer patients: description and comparison with the Charlson's index. Br J Cancer 2005;93:1098-1105.

27. Sorror ML, Maris MB, Storb R, et al. Hematopoietic cell transplantation (HCT)-specific comorbidity index: a new tool for risk assessment before allogeneic HCT. Blood 2005;106:2912-2919.

28. Sachdev M, Sun JL, Tsiatis AA, et al. The prognostic importance of comorbidity for mortality in patients with stable coronary artery disease. J Am Coll Cardiol 2004;43:576-582.

29. Liu J, Huang Z, Gilbertson DT, et al. An improved comorbidity index for outcome analyses among dialysis patients. Kidney Int 2010;77:141-151.

30. Saklad M. Grading of patients for surgical procedures. Anesthesiology 1941;2:281-284.

31. Piccirillo JF, Tierney RM, Costas I, et al. Prognostic importance of comorbidity in a hospital-based cancer registry. JAMA 2004;291:2441-2447.

32. Oken MM, Creech RH, Tormey DC, et al. Toxicity and response criteria of the Eastern Cooperative Oncology Group. Am J Clin Oncol 1982;5:649-655.

33. Mayr R, May M, Martini T, et al. Predictive capacity of four comorbidity indices estimating perioperative mortality after radical cystectomy for urothelial carcinoma of the bladder. BJU Int 2012;110:E222-227.

34. Psutka SP, Carrasco A, Schmit GD, et al. Sarcopenia in patients with bladder cancer undergoing radical cystectomy: impact on cancer-specific and all-cause mortality. Cancer 2014;120:2910-2918.

35. Chappidi MR, Kates M, Patel HD, et al. Frailty as a marker of adverse outcomes in patients with bladder cancer undergoing radical cystectomy. Urol Oncol 2016;34:256 e1-6.

See JNCCN.org for supplemental online content. 